\title{
FAKTOR-FAKTOR YANG BERHUBUNGAN DENGAN MOTIVASI PERAWAT UNTUK MELANJUTKAN PENDIDIKAN TINGGI KEPERAWATAN DI RSUD ENCIK MARIYAM TAHUN 2020
}

\author{
Siska Zalina ${ }^{1}$, Sri Muharni ${ }^{2}$, Utari Christya Wardhani ${ }^{3}$ \\ Program Studi Ilmu Keperawatan STIKes Awal Bros Batam \\ Emailkorespondensi: siskazalina@gmail.com
}

\begin{abstract}
ABSTRAK
Berdasarkan PERMENKES RI Nomor 40 Tahun 2017 Tentang aturan hak dan kewajiban perawat dalam meningkatkan mutu pelayanan dengan peningkatan pendidikan lanjutan, maka diharapkan perawat memiliki motivasi yang tinggi untuk dapat melanjutkan pendidikan lanjutan pada program pendidikan keperawatan. Tujuan penelitian diketahuinya hubungan tingkat persaingan, dukungan keluarga dan reward dengan motivasi perawat untuk melanjutkan pendidikan tinggi keperawatan di RSUD Encik Mariyam Tahun 2020. Desain penelitian menggunakan metode deskriptif korelasi dengan pendekatan cross sectional, pemilihan sampel dengan tekhik Total sampling, jumlah sampel 49 responden. Hasil penelitian diuji dengan uji Spearman Rho dan menunjukkan Persaingan memiliki nilai korelasi coefficient sebesar 0,828. arah hubungan antara persaingan dengan motivasi perawat adalah positif, dukungan keluarga memiliki nilai korelasi coefficient sebesar 0, 743. arah hubungan antara dukungan keluarga dengan motivasi perawat adalah positif. Reward memiliki nilai korelasi coefficient sebesar 0,954. arah hubungan antara reward dengan motivasi perawat adalah positif. Diharapkan kepada RSUD Encik Mariyam Kabupaten Lingga agar melakukan sosialisasi kepada perawat tentang kebijakan melanjutkan pendidikan keperawatan. Kepada perawat diharapkan memiliki motivasi yang tinggi untuk melanjutkan pendidikan lanjutan di bidang keperawatan guna meningkatkan pelayanan keperawatan yang lebih baik. Kepada peneliti selanjutnya agar dapat menggali lebih dalam lagi faktor faktor yang berhubungan dengan motivasi perawat untuk melanjutkan pendidikan tinggi keperawatan di RSUD Encik Maryam.
\end{abstract}

Kata kunci: Perawat, motivasi, pendidikan, reward

\section{RELATED FACTORS TO NURSES' MOTIVATION IN CONTINUING NURSING EDUCATION IN ENCIK MARIYAM HOSPITAL YEAR 2020}

\author{
Siska Zalina ${ }^{1}$, Sri Muharni ${ }^{2}$, Utari Chystya Wardhani ${ }^{3}$ \\ Nursing Study Program at Awal Bros Batam College of Health Sciences \\ Emailcorrespondence: siskazalina@gmail.com
}

\begin{abstract}
Based on the Regulation of the PERMENKES RI Number 40 of 2017 concerning the rules for the rights and obligations of nurses in improving the quality of service by increasing further education, it is hoped that nurses will have high motivation to be able to continue further education in the nursing education program. The research objective was to determine the relationship between the level of competition, family support and reward with the motivation of nurses to continue nursing higher education at Encik Mariyam Hospital in 2020. The research design used a descriptive correlation method with a cross-sectional approach, the sample selection was with a total sampling technique, a sample size of 49 respondents. The results were tested with the Spearman Rho test and showed that competition had a correlation coefficient value of 0.828 . The direction of the relationship between competition and nurses 'motivation is positive, family support has a correlation coefficient value of 0.743. The direction of the relationship between family support and nurses' motivation is positive. Reward has a correlation coefficient value of 0.954. the direction of the relationship between reward and nurse motivation is positive. It is hoped that the Encik Mariyam Regional Hospital of Lingga Regency will conduct outreach to nurses about the policy of continuing nursing education. It is hoped that nurses will have
\end{abstract}


high motivation to continue further education in nursing education programs in order to improve better nursing services. To the next researchers, in order to dig deeper into the factors related to the motivation of nurses to continue nursing higher education at Encik Maryam Hospital, in order to support the increase in nursing staff who are more competent with higher levels of education

Words key : Nurse, motivation, education, reward

\section{PENDAHULUAN}

Kualitas pelayanan kesehatan sangat berkaitan erat dengan kualitas tenaga pemberi layanan kesehatan. Perawat dalam melaksanakan praktik keperawatan diharakan senantiasa meningkatkan mutu pelayanan dengan mengikuti perkembangan Ilmu Pengetahuan dan Teknologi (IPTEK) melalui pendidikan serta pelatihan yang sesuai dengan bidang tugasnya, yang diselenggarakan oleh Organisasi Profesi keperawatan, Pemerintah Daerah atau Pemerintah (Permenkes, 2019). Berdasarkan Undang-Undang Republik Indonesia Nomor 12 Tahun 2012 mengenai Pendidikan Tinggi dan Peraturan Menteri Kesehatan Republik Indonesia Nomor 40 Tahun 2017 mengenai Pengembangan Jenjang Karir Profesional Perawat Klinis yang menegaskan tentang aturan hak dan kewajiban perawat dalam meningkatkan mutu pelayanan dengan peningkatan pendidikan lanjutan, maka diharapkan perawat memiliki semangat atau motivasi yang baik agar dapat melanjutkan pendidikan lanjutan pada program pendidikan ilmu keperawatan.

Kelanjutan pendidikan keperawatan dipengaruhi oleh beberapa faktor, salah satunya adalah motivasi. Motivasi merupakan kekuatan psikologis yang menggerakkan seseorang ke beberapa jenis tindakan. Motivasi berfokus pada berbagai faktor atau kebutuhan dalam diri seseorang untuk menumbuhkan semangat, mengarahkan, mempertahankan, serta menghentikan perilaku (Nursalam 2016). Motivasi memiliki tiga unsur penting, yaitu kebutuhan, dorongan, dan tujuan. (Supriyono, 2016).

Faktor-faktor yang dapat mempengaruhi motivasi perawat dalam melanjutkan pendidikan adalah Persaingan, Kemampuan finansial, dukungan keluarga, dukungan METODE PENELITIAN perusahaan, dan reward dari melanjutkan pendidikan. (Supriyono, 2016).

Wulandari dan Pujasari (2015) yang dilakukan di Fakultas Ilmu Keperawatan Universitas Indonesia menyatakan bahwa ada hubungan antara kemampuan finansial dengan motivasi perawat dalam melanjutkan pendidikan. Penelitian ini menjelaskan bahwa perawat yang memiliki kemampuan ekonomi menengah sampai bawah menjadi faktor penghambat mereka dalam melanjutkan pendidikan. Penelitian yang dilakukan oleh Fatmawati (2016) di RSUD Syekh Yusuf Gowa Makassar menunjukkan bahwa terdapat hubungan yang signifikan antara dukungan keluarga dengan motivasi perawat dalam melanjutkan pendidikan. Penelitian ini menjelaskan bahwa setiap orang membutuhkan dukungan atau dorongan dari orang terdekat. Hal ini juga akan mempengaruhi seseorang dalam mengambil keputusan termasuk keputusan dalam melanjutkan pendidikan.

Dari hasil wawancara yang dilakukan kepada Komite Keperawatan RSUD Encik Mariyam tampak pendidikan perawat di RSUD Encik Mariyam masih banyak lulusan D III Keperawatan yang perlu ditingkatkan lagi ke jenjang pendidikan yang lebih tinggi. Berdasarkan uraian diatas maka peneliti ingin menggali lebih dalam lagi dengan melakukan penelitian tentang faktor-faktor yang berhubungan dengan motivasi perawat untuk melanjutkan pendidikan tinggi keperawatan di RSUD Encik Maryam Tahun 2020 .

Penelitian ini bertujuan untuk mengetahui faktor-faktor yang berhubungan dengan motivasi perawat untuk melanjutkan pendidikan tinggi keperawatan di RSUD Encik Mariyam Tahun 2020. 
Penelitian yang dilakukan adalah penelitian observasional dengan desain non-experiment studi korelasi. Jenis penelitian yag digunakan adalah deskriptif korelasional dan pendekatan adalah cross sectional dimana peneliti mencoba menggali adanya Faktor-faktor yang

Alat pengumpulan data berupa kuesioner yang dibagikan terhadap responden. Hasil berhubungan dengan motivasi perawat untuk melanjutkan pendidikan tinggi keperawatan di RSUD Encik Mariyam Tahun 2020 (Nursalam, 2014). Pemilihan sampel dengan tekhik Total sampling, jumlah sampel sebanyak 49 responden.

penelitian diuji dianalisa dengan uji Spearman Rho

\section{HASIL DAN PEMBAHASAN}

\section{Analisa Univariat}

1. Frekuensi karakteristik responden

Tabel 4.1

Distribusi Frekuensi Karakteristik Usia, Jenis Kelamin, Pendidikan, Lama Bekerja, Pendapatan, dan Status Kepegawaian

\begin{tabular}{|c|c|c|c|}
\hline No & Karakteristik & Frekuensi (f) & Persentase $(\%)$ \\
\hline \multirow[t]{4}{*}{1} & Usia & & \\
\hline & a. 20 - 30 Tahun & 10 & 20,41 \\
\hline & b. $31-40$ Tahun & 26 & 53,06 \\
\hline & c. 41 - 50 Tahun & 13 & 26,53 \\
\hline \multirow[t]{3}{*}{2} & Jenis kelamin & & \\
\hline & a. Laki laki & 16 & 32,65 \\
\hline & b. Perempuan & 33 & 67,35 \\
\hline \multirow[t]{3}{*}{3} & Pendidikan & & \\
\hline & a. D III Keperawatan & 46 & 93,88 \\
\hline & b. Skep & 3 & 6,12 \\
\hline \multirow[t]{5}{*}{4} & Lama Bekerja & & \\
\hline & a. $<1$ Tahun & 6 & 12,24 \\
\hline & b. 1 - 5 Tahun & 14 & 28,57 \\
\hline & c. 6 - 10 Tahun & 22 & 44,90 \\
\hline & d. $11-15$ Tahun & 7 & 14,29 \\
\hline \multirow[t]{3}{*}{4} & Pendapatan & & \\
\hline & a. $<3$ Juta/Bulan & 18 & 36,73 \\
\hline & b. > 3 Juta/Bulan & 31 & 63,27 \\
\hline \multirow[t]{3}{*}{5} & Status pegawai & & \\
\hline & a. Honorer/ TKHL & 18 & 36,73 \\
\hline & b. PNS & 31 & 63,27 \\
\hline
\end{tabular}

Berdasarkan tabel 4.1 diatas dapat diketahui responden dengan distribusi karakteristik Usia terbanyak yaitu pada usia 31-40 tahun yaitu 26 orang $(53,06 \%)$, distribusi karakteristik Jenis kelamin terbanyak dengan jenis kelamin perempuan yaitu 33 orang $(67,35 \%)$, distribusi karakteristik pendidikan terbanyak yaitu DIII Keperawatan sebanyak 46 orang $(93,88 \%)$, distribusi karakteristik lama bekerja terbanyak yaitu 6-10 tahun sebanyak 22 orang (44,90\%), distribusi karakteristik pendapatan terbanyak yaitu $>3$ juta/bulan yaitu sebanyak 31 orang $(63,27 \%)$ dan distribusi karakteristik status pegawai terbanyak yaitu PNS sebanyak 31 orang $(63,27 \%)$. 
2. Frekuensi karakteristik faktor persaingan, dukungan keluarga, reward, dan motivasi.

Tabel 4.2

Distribusi frekuensi karakteristik responden berdasarkan Faktor persaingan, dukungan keluarga, reward dan motivasi

\begin{tabular}{|c|c|c|c|}
\hline No & Variabel & frekuensi & persentase \% \\
\hline \multirow[t]{5}{*}{1} & Persaingan & & \\
\hline & 1. Tinggi & 14 & 28,57 \\
\hline & 2. Sedang & 25 & 51,02 \\
\hline & 3. Rendah & 10 & 20,41 \\
\hline & Total & 49 & 100 \\
\hline \multirow[t]{5}{*}{2} & Dukungan keluarga & & \\
\hline & a. Tinggi & 24 & 49,00 \\
\hline & b. Sedang & 16 & 32,6 \\
\hline & c. Rendah & 9 & 18,4 \\
\hline & Total & 49 & 100 \\
\hline \multirow[t]{5}{*}{3} & Reward & & \\
\hline & 1. Tinggi & 24 & 49,00 \\
\hline & 2. Sedang & 15 & 30,6 \\
\hline & 3. Rendah & 10 & 20,4 \\
\hline & Total & 49 & 100 \\
\hline \multirow[t]{5}{*}{4} & Motivasi & & \\
\hline & a. Tinggi & 24 & 49,00 \\
\hline & b. Sedang & 15 & 30,6 \\
\hline & c. Rendah & 10 & 20,4 \\
\hline & Total & 49 & 100 \\
\hline
\end{tabular}

Berdasarkan tabel 4.2 didapatkan hasil distribusi frekuensi karakteristik responden berdasarkan faktor persaingan terbanyak yaitu pesaingan sedang sebanyak 25 orang $(51,02 \%)$, dukungan keluarga terbanyak yaitu dukungan tinggi sebanyak 24 orang $(49,00 \%)$, reward terbanyak yaitu reward tinggi sebanyak 24 orang $(49,00 \%)$, dan frekuensi variabel motivasi terbanyak adalah tinggi yaitu sebanyak 24 orang $(49,00 \%)$.

\section{Analisa Bivariat}

1. Hubungan persaingan dengan motivasi perawat melanjutkan pendidikan tinggi keperawatan di RSUD Encik Mariyam Tahun 2020 
Tabel 4.3

Tabel silang persaingan dan motivasi perawat melanjutkan pendidikan tinggi Keperawatan

\begin{tabular}{lrrrrr}
\hline \multirow{2}{*}{ Persaingan } & \multicolumn{3}{c}{ Motivasi } & \multicolumn{2}{c}{ Total } \\
\cline { 2 - 5 } Rendah & \multicolumn{2}{c}{ Rendah } & Sedang & Tinggi & 10 \\
& & 10 & 0 & 0 & $20.4 \%$ \\
\multirow{2}{*}{ Sedang } & $20.4 \%$ & $0.0 \%$ & $0.0 \%$ & 25 \\
\multirow{2}{*}{ Tinggi } & $0.0 \%$ & 13 & 12 & $51.0 \%$ \\
& \multirow{2}{*}{ Total } & 0 & $26.5 \%$ & $24.5 \%$ & 14 \\
& $0.0 \%$ & 0 & 14 & $28.6 \%$ \\
\hline & 10 & $0.0 \%$ & $28.6 \%$ & 49 \\
& $20.4 \%$ & $26.5 \%$ & $53.1 \%$ & $100.0 \%$ \\
\hline
\end{tabular}

Berdasarkan tabel diatas diketahui sebagian responden memiliki tingkat persaingan tinggi dan motivasi tinggi (28.6\%) dan hasil analisa Uji Spearman Rho dengan menggunakan bantuan SPSS, diperoleh nilai Signifikansi 0.000. Suatu variabel dikatakan berhubungan signifikan jika nilai signifikansi yang dimiliki lebih kecil dari tingkat probabilitas $5 \%(0,05)$. Dengan ketentuan tersebut dapat diartikan bahwa persaingan memiliki hubungan yang signifikan (nyata/bermakna) terhadap motivasi perawat karena memiliki signifikansi yang lebih kecil dari 0.05 yaitu 0.000 .

2. Hubungan Dukungan Keluarga dengan Motivasi perawat melanjutkan pendidikan tinggi keperawatan di RSUD Encik Mariyam Tahun 2020.

Tabel 4.4

Tabel silang dukungan keluarga dan motivasi perawat melanjutkan pendidikan tinggi Keperawatan

\begin{tabular}{|c|c|c|c|c|}
\hline \multirow{2}{*}{ Dukungan keluarga } & \multicolumn{3}{|c|}{ Motivasi } & \multirow{2}{*}{ Total } \\
\hline & Rendah & Sedang & Tinggi & \\
\hline \multirow{2}{*}{ Rendah } & 5 & 0 & 0 & 10 \\
\hline & $10.2 \%$ & $0.0 \%$ & $0.0 \%$ & $10.2 \%$ \\
\hline \multirow{2}{*}{ Sedang } & 5 & 11 & 0 & 16 \\
\hline & $10.2 \%$ & $22.4 \%$ & $0.0 \%$ & $32.7 \%$ \\
\hline \multirow{2}{*}{ Tinggi } & 0 & 2 & 26 & 28 \\
\hline & $0.0 \%$ & $4.1 \%$ & $53.1 \%$ & $57.1 \%$ \\
\hline \multirow{2}{*}{ Total } & 10 & 13 & 26 & 49 \\
\hline & $20.4 \%$ & $26.5 \%$ & $53.1 \%$ & $100.0 \%$ \\
\hline
\end{tabular}

Berdasarkan tabel diatas diketahui lebih dari setengah responden memiliki tingkat dukungan keluarga tinggi dan motivasi tinggi (53.1\%) dan hasil analisa Uji Spearman Rho dengan 
menggunakan bantuan SPSS, diperoleh nilai Signifikansi 0.000. Suatu variabel dikatakan berhubungan signifikan jika nilai signifikansi yang dimiliki lebih kecil dari tingkat probabilitas $5 \%(0,05)$. Dengan ketentuan tersebut dapat diartikan bahwa dukungan keluarga memiliki hubungan yang signifikan (nyata/bermakna) terhadap motivasi perawat karena memiliki nilai signifikansi yang lebih kecil dari 0.05 yaitu 0.000 .

3. Hubungan Reward dengan Motivasi perawat melanjutkan pendidikan tinggi keperawatan di RSUD Encik Mariyan Tahun 2020.

Tabel 4.5

Tabel silang reward dan motivasi perawat melanjutkan pendidikan tinggi Keperawatan

\begin{tabular}{lrrrrr}
\hline \multirow{2}{*}{ Reward } & \multicolumn{3}{c}{ Motivasi } & \multirow{2}{*}{ Total } \\
\cline { 2 - 5 } Rendah & \multicolumn{1}{c}{ Rendah } & Sedang & Tinggi & 10 \\
& & 10 & 0 & 0 & $20.4 \%$ \\
\multirow{2}{*}{ Sedang } & $20.4 \%$ & $0.0 \%$ & $0.0 \%$ & 13 \\
\multirow{2}{*}{ Tinggi } & $0.0 \%$ & 13 & 0 & $26.5 \%$ \\
& \multirow{2}{*}{ Total } & 0 & $26.5 \%$ & $0.0 \%$ & 26 \\
& $0.0 \%$ & 0 & 26 & $53.1 \%$ \\
\hline
\end{tabular}

Berdasarkan tabel diatas diketahui lebih dari setengah responden memiliki tingkat persepsi reward tinggi dan motivasi tinggi $(53.1 \%)$ dan hasil analisa Uji Korelasi Spearman Rho dengan menggunakan bantuan SPSS, diperoleh nilai Signifikansi 0.000. Suatu variabel dikatakan berhubungan signifikan jika

\section{PEMBAHASAN}

1. Analisa Univariat

a. Analisa persaingan perawat

Dari hasil penelitian didapatkan hasil distribusi frekuensi karakteristik responden berdasarkan faktor persaingan terbanyak yaitu persaingan sedang sebanyak 25 orang $(51,02 \%)$. Berdasarkan penelitian Fatmawati (2016) dengan judul Faktor-faktor yang berhubungan dengan motivasi perawat melanjutkan pendidikan ke jenjang $\mathrm{S} 1$ keperawatan di ruang irna Rsud Syekh Yusuf Gowa Tahun 2016 data yang diperoleh data sebanyak 26 orang $(68,4 \%)$ responden yang mempunyai motivasi yang tinggi untuk melanjutkan pendidikan, yang termasuk dalam kategori persaingan tinggi sebanyak 16 orang nilai signifikansi yang dimiliki lebih kecil dari tingkat probabilitas 5\% (0,05). Maka dengan ketentuan tersebut dapat diartikan bahwa reward memiliki hubungan yang signifikan (nyata/bermakna) terhadap motivasi perawat karena memiliki signifikansi yang lebih kecil dari 0.05 yaitu 0.000 .

$(42,1 \%)$ responden. Hasil Uji Chi-Square menunjukkan bahwa adanya hubungan faktor persaingan dengan motivasi perawat untuk melanjutkan pendidikan keperawatan di ruang IRNA RSUD Syekh Yusuf Kabupaten Gowa dengan nilai $\mathrm{p}$ lebih kecil dari 0,05. Dari pendapat para ahli dan peneliti sebelumya diatas, peneliti berasumsi bahwa dengan adanya persaingan yang tinggi dapat menjadi salah satu faktor motivasi perawat dalam melanjutkan pendidikan tinggi keperawatan di RSUD Encik Mariyam Lingga. Persaingan bisa saja terjadi karena adanya ambisi untuk mendapatkan penghargaan, pengakuan, serta status sosial yang lebih baik. 
b. Analisa dukungan keluarga

Dari hasil penelitian diperoleh data bahwa dukungan keluarga terbanyak yaitu dukungan tinggi sebanyak 24 orang $(49,00 \%)$. Hal ini sejalan dengan penelitian yang dilakukan oleh Rahmiati dengan judul Faktor-faktor Yang Mempengaruhi Minat Mahasiswa Semester VIII Program Studi ( Prodi ) Ilmu Keperawatan Untuk Melanjutkan Pendidikan ke Program Ners di Universitas Islam Negeri Alauddin Makassar (2015) bahwa terdapat hubungan yang bermakna antara faktor dukungan keluarga terhadap minat mahasiswa dalam melanjutkan pendidikan ke program Ners. Dengan demikian peneliti berasumsi bahwa faktor dukungan keluarga sangat berpengaruh terhadap motivasi perawat dalam melanjutkan pendidikan tinggi keperawatan di RSUD Encik Mariyam Lingga. Data menunjukkan bahwa dukungan keluarga mempunyai pengaruh terhadap motivasi seseorang dalam melanjutkan pendidikan. Dukungan serta dorongan dari orang-orang terdekat sangat mempengaruhi seseorang dalam mengambil keputusan termasuk keputusan dalam melanjutkan pendidikan.

\section{c. Analisa faktor reward}

Dari hasil penelitian didapatkan hasil rewad terbanyak pada kriteria tinggi sebanyak 24 orang $(49,00 \%)$. Penelitian ini sama dengan penelitian Febria Novita (2017) tentang "Faktor-faktor yang berhubungan dengan motivasi perawat melanjutkan Pendidikan kejenjang Sarjana Keperawatan dan Ners di Lingkungan Dinas Kesehatan Kota Padang" dengan hasil penelitiannya yaitu $p=0,027$, hal ini berarti terdapat hubungan yang bermakna antara faktor penghargaan ( reward) dengan motivasi melanjutkan pendidikan. Asumsi peneliti terhadap hasil penelitian yang telah dilakukan dapat disimpulkan bahwa seseorang (responden) dalam melanjutkan pendidikan perlu dukungan dari pihak Rumah Sakit dalam bentuk reward, karena dengan adanya reward akan meningkatkan motivasi perawat dalam melanjutkan pendidikan.

\section{Analisa bivariat}

a. Hubungan persaingan dengan motivasi

Berdasarkan hasil Uji Spearman Rho dengan menggunakan bantuan Spss, diperoleh nilai Signifikansi=0,000. Suatu variabel dikatakan berhubungan signifikan jika nilai signifikansi yang dimiliki lebih kecil dari tingkat probabilitas 5\% (0,05). Dari ketentuan tersebut bisa diartikan bahwa persaingan memiliki hubungan yang signifikan (nyata/bermakna) terhadap motivasi perawat karena memiliki nilai signifikansi yang lebih kecil dari 0,05 yaitu 0,000.

Dari hasil Uji Korelasi Spearman Rho bisa dilihat bahwa persaingan memiliki nilai korelasi coefficient sebesar 0,828. Sehingga dapat diketahui bahwa arah hubungan antara persaingan dengan motivasi perawat adalah positif. Hal ini berarti jika persaingan seorang perawat tinggi maka motivasi perawat dalam melanjutkan pendidikan tinggi keperawatan juga meningkat.

b. Hubungan dukungan keluarga dengan motivasi

Berdasarkan hasil Uji Spearman Rho dengan menggunakan bantuan Spss, diperoleh nilai Signifikansi $=0.000$. Suatu variabel dikatakan berhubungan signifikan jika nilai signifikansi yang dimiliki lebih kecil dari tingkat probabilitas 5\% (0,05). Maka dari ketentuan tersebut diartikan bahwa dukungan keluarga memiliki hubungan yang signifikan (nyata/bermakna) terhadap motivasi perawat karena memiliki signifikansi yang lebih kecil dari 0,05 yaitu 0,000 .

Dari hasil Uji Korelasi Spearman Rho dapat dilihat bahwa dukungan keluarga memiliki nilai korelasi coefficient sebesar 0,743. Sehingga dapat diketahui bahwa arah hubungan antara dukungan keluarga dengan motivasi perawat adalah positif. Hal ini berarti jika dukungan keluarga tinggi berarti motivasi perawat dalam melanjutkan pendidikan tinggi keperawatan akan meningkat juga.

c. Hubungan reward dengan motivasi

Berdasarkan hasil Uji Korelasi Spearman Rho dengan menggunakan bantuan Spss, diperoleh nilai Signifikansi $=0.000$. Suatu 
variabel dikatakan berhubungan signifikan jika miliki nilai signifikansi yang lebih kecil dari tingkat probabilitas 5\% (0.05). Maka dengan ketentuan tersebut dapat diartikan bahwa reward memiliki hubungan yang signifikan (nyata/bermakna) terhadap motivasi perawat karena memiliki signifikansi yang lebih kecil dari 0,05 yaitu 0,000 .

\section{SIMPULAN}

1. Dari hasil Uji Korelasi Spearman Rho dapat dilihat Persaingan memiliki nilai korelasi coefficient sebesar 0,828 . Sehingga dapat diketahui bahwa arah hubungan antara persaingan dengan motivasi perawat adalah positif. Hal ini berarti bila ada persaingan perawat yang tinggi maka motivasi perawat dalam melanjutkan pendidikan tinggi keperawatan juga akan meningkat.

2. Dari hasil Uji Korelasi Spearman Rho dapat dilihat bahwa dukungan keluarga memiliki nilai korelasi coefficient sebesar 0,743. Sehingga dapat diketahui bahwa arah hubungan antara dukungan keluarga dengan motivasi perawat adalah positif. Hal ini berarti jika dukungan keluarga tinggi maka motivasi perawat melanjutkan pendidikan tinggi keperawatan akan meningkat juga.

3. Dari hasil Uji Korelasi Spearman Rho dapat dilihat bahwa reward memiliki nilai korelasi coefficient sebesar 0,954 . Sehingga dapat diketahui bahwa arah hubungan antara reward dengan motivasi perawat adalah positif. Hal ini berarti jika reward tinggi maka motivasi perawat untuk melanjutkan pendidikan tinggi keperawatan juga akan meningkat.

\section{UCAPAN TERIMAKASIH}

1. Prof.Dr.Fadil Oenzil,PhD.Sp.GK selaku Ketua Stikes Awalbros Batam.

2. Sri Muharni, Ners, M.Kep selaku Ka. Prodi Sarjana Keperawatan Stikes Awalbros Batam.

3. Sri Muharni, Ners, M.Kep selaku pembimbing I.

4. Utari CH Wardhani, Ners, M.Kep selaku pembimbing II.
Dari hasil Uji Korelasi Spearman Rho dapat dilihat bahwa reward memiliki nilai korelasi coefficient sebesar 0,954. Sehingga dapat diketahui bahwa arah hubungan antara reward dengan motivasi perawat adalah positif. Hal ini berarti jika reward tinggi maka motivasi perawat untuk melanjutkan pendidikan tinggi keperawatan juga akan meningkat.

5. dr.Suryadi selaku direktur RSUD Encik Mariyam.

6. Seluruh Dosen Pengajar yang sudah mendukung proses penyusunan Skripsi ini dari awal hingga akhir.

7. Keluarga tercinta, suami dan anak - anak tersayang yang sudah memberikan dukungan dalam penyusunan Skripsi ini hingga selesai.

8. Seluruh Mahasiswa Sarjana Keperawatan Angkatan XI Stikes Awalbros

\section{DAFTAR PUSTAKA}

Abu Ahmadi dan Supriyono. 2014. Psikologi Belajar. Jakarta: PT. Rineka Cipta.

Bakri, M. H. (2017). Manajemen Keperawatan (Konsep dan Aplikasi dalam Praktik Keperawatan Profesional). Yogyakarta: Pustaka Baru Press.

Dharma, K. 2015. Metodologi Penelitian Keperawatan. Jakarta: CV. Trans Info Media.

Fatmawati. 2012. Faktor Yang Berhubungan Dengan Motivasi Perawat Untuk Melanjutkan Pendidikan ke Jenjang Sarjana Keperawatan di RSUD Syekh Yusuf Kabupaten Gowa Tahun 2012. SkipsiFakultas Ilmu Kesehatan Universita Islam Negeri Alauddin Makassar.

Harahap, Ali Syabana. (2014). Pengaruh Motivasi Belajar Terhadap Hasil Belajar Siswa Pada Mata Pelajaran Kearsipan SMK Swasta Satria Dharma Perbaungan T.P 2013/2014. Skripsi Universitas Negeri Medan.

Hasibuan, Malayu S.P. 2009. Manajemen sumber daya manusia. Edisi 11. Jakarta: PT Bumi Aksara.

Hicks, G, H \& Gullet, R, G, Apriyanto. 2016. Organisasi; Teori dan Tingkah Laku. Edisi. 
Ketiga. Jakarta: Bumi Aksara. Huang, C.C. You, C.S.

Kementrian Kesehatan RI. (2017). Situasi Tenaga Keperawatan. Info Datin, 1-12.

Kompri. 2016. Motivasi Pembelajaran.Bandung: Remaja Rosdakarya.

Kusnanto. 2015. Pengantar Profesi dan praktik keperawatan profesional. Jakarta: Buku Kedokteran EGC

Makatiho, J. G., Tilaar, C., \& Ratag, B. (2015). Motivasi kerja Perawat di Instalasi rawat inap C 1-10

Marbun, Nova Delima. (2014). Pengaruh Motivasi Belajar Terhadap Prestasi Belajar Siswa Pada Mata Pelajaran Ekonomi Di Kelas XI IPS SMA Negeri 2 Sidikalang T.P 2013/2014. Skripsi Universitas Negeri Medan.

Mohamad Sukriyant, Isa, dkk, (2014). FaktorFaktor yang Berhubungan dengan Motivasi Perawat D3 untuk melanjutkan pendidikan ke Jenjang S1 Keperawatan di Rawat Inap RSUD DR. M. Dunda Kabupaten Gorontalo Tahun 2014. Skipsi Universitas Negri Gorontalo.

Notoatmodjo, S. 2014. Metodologi penelitian kesehatan. Jakarta: PT Rineka Cipta.

Nursalam. 2016. Konsep dan Penerapan Metodologi Penelitian Ilmu Keperawatan: Pedoman Skripsi, Tesis dan Instrumen Penelitian Keperawatan Edisi 1. Jakarta: Salemba Medika.

Rhona Sandra. 2018. Faktor-Faktor yang Berhubungan dengan Motivasi Mahasiswa Melanjutkan Pendidikan Ners di STIKes Syedza Saintika Padang Tahun 2017. Jurnal Keperawatan.
Sardiman, AM. 2014. Interaksi dan Motivasi Belajar Mengajar. Bandung: Raja Grafindo Persada.

Silaban, Reny Yatnasari, dkk. (2016). Hubungan motivasi mahasiswa program sarjana keperawatan dengan Minat Melanjutkan Studi Profesi Ners di Program Studi Ilmu Keperawatan Sam Ratulangi Manado. Jurnal Keperawatan.

Sugiyono. 2014. Metode penelitian kuantitatif kuanlitatif dan R \& B. Bandung: Alfa Beta

Suprayanto.2015. Konsep motivasi. http://drsuprayanto.com/2015/09/

konsepmotivasi.html. Diunduh 12 November 2019.

Supriyanti. 2015. Faktor-Faktor yang Berhubungan dengan Motivasi Perawat Melanjutkan Pendidikan Tinggi Keperawatan di Rumah Sakit Islam Surakarta. Fakultas Ilmu Kesehatan Universitas Muhammadiyah Surakarta.

Tri Putra, Riko. 2015. Analisis Faktor Motivasi Mahasiswa Program B Tahun Angkatan 2014 - 2015 Dalam Melanjutkan Pendidikan Ke Jenjang S1 Keperawatan di Fakultas Keperawatan Unand Padang Tahun 2015. Skripsi Fakultas Keperawatan Unand.

Uno, Hamzah. 2014. Teori motivasi dan Pengukurannya. Jakarta: PT.Bumi Aksara.

Wirawan. 2015. Manajemen Sumber Daya Manusia Indonesia. Jakarta: PT.Raja Grafindo Persada.

Witjaksono, A. A. M. R., Hartiningsih, D. S. S., \& Indriana, G. 2017. Hubungan Motivasi Kerja dengan Kinerja Perawat Instalasi Rawat Inap di Pusat Mata Nasional Rumah Sakit Cicendo Bandung Tahun 2017, 1-17. 